\title{
Pesticide-Contaminated Food a Serious Health Hazard in World
}

\section{Danial $Z^{1}$, Kalantar Motamedi MH* ${ }^{2}$, Koshmohabat $\mathbf{H}^{3}$, Mirhashemi $\mathbf{S}^{4}$, Danial $\mathbf{N}^{5}$, Zamanian $\mathbf{H}^{6}$}

${ }^{1} \mathrm{PhD}$, Faculty of Trauma Research Center, Baqiyatallah University of Medical Sciences and Allameh Tabataba'i University, Faculty of Psychology \& Educational Science

Dehkadeh-ye-OlympicDehkadeh-ye-Olympic, Tehran, Iran

${ }^{* 2}$ Professor Trauma Research Center, Baqiyatallah University of Medical Sciences, Tehran, Iran

${ }^{3}$ Assistant Professor in Trauma Surgery, Trauma Research Center, Baqiyatallah University of Medical Sciences, Tehran, Iran

${ }^{4} \mathrm{MD}$, Faculty of Trauma Research Center, Baqiyatallah University of Medical Sciences, Tehran, Iran ${ }^{5}$ MS, Esavand School, Ministry of Educational and Development. Share Ghods, Tehran, Iran ${ }^{6} \mathrm{MS}$, Besharat School, Ministry of Educational and Development. Mashhad, Iran

Pesticides are used to kill the pests and insects which attack on crops and harm them. Different kinds of pesticides have been used for crop protection for centuries. Pesticides benefit the crops; however, they also impose a serious negative impact on the environment. Excessive use of pesticides may lead to the destruction of biodiversity. Many birds, aquatic organisms and animals are under the threat of harmful pesticides for their survival. Many birds, aquatic organisms and animals are under the threat of harmful pesticides for their(1). In every society, food security and adequate access to healthy foods and certainty of supervision for food safety is imperative to health. While public food safety and health are directly related to the type of food intake, many diseases and microbes transmitted through contaminated foods can transfer dangerous viruses and bacteria with meat, vegetables and fruit. More importantly food must be free of chemical pesticide contamination. Production of healthy foods must start from the early stages of cultivation and continue to until factory processing. (2) The absorption of chemical pesticides and contaminants may cause toxicity, responsible for the increasing prevalence of other serious illnesses, especially cancer both directly and indirectly. Other illnesses from pesticide contamination include genetic disorders, infertility, neurological and psychiatric disorders, memory loss, idleness in children, immune system disorders, allergies and hormonal disorders; absorption of residual pesticides by air, soil and water leads to a vicious cycle. Then, milk, meat and agricultural products can become contaminated and enter the food chain.(3) Ozekeke Ogbeide showed that Risk estimates using ILCR and CDI showed that the risk of cancer and noncancer effects was highest when exposure route was through ingestion. Furthermore, model projections highlights children as high risk population groups for non-dietary exposure to $\operatorname{OCPs}(4)$. Unfortunately, currently in Iran there is no central organization to monitor toxins ; Use of agricultural pesticides in Iran Compared with Countries with similar GDP is higher.(3) .Thus, the creation of control centers in the country is acutely necessary. Actions in this regard needs serious implementation: Lack of sufficient control and use of pesticide residues and contaminants in food, lack of proper and adequate system for data collection and observation on use of pesticides and chemical fertilizers, policies and regulations on the use of chemical pesticides and how to use them more carefully must be addressed. Processing use of hormones in meat and vegetables is also important for consumers. (5) Rules and regulation and a strict supervision system are necessary. Policy makers should take actions in this regard. This means that the government ministries and policymakers must become involved. A bill must be sent to Parliament, then legally approved and enforced by the judiciary system to standardize food safety. 


\section{REFERENCES}

[1] Mahmood, I., Imadi, S. R., Shazadi, K., Gul, A., \& Hakeem, K. R. (2016). Effects of Pesticides on Environment. In Plant, Soil and Microbes (pp. 253-269). Springer International Publishing.

[2] Omidvar N(2015), Centers need to measure pollutants and toxins in food, Agricultural Engineering Magazine, Number 68,p:22(In Persian)

[3] http://www.uiccp.ir/index.php/news.html Diop, A., Diop, Y. M., Thiaré, D. D., Cazier, F., Sarr, S. O., Kasprowiak, A., ... \& Delattre, F. (2016). Monitoring survey of the use patterns and pesticide residues on vegetables in the Niayes zone, Senegal. Chemosphere, 144, 1715-1721.

[4] morowati M \& Azadvar M(2013), Determination of Diazinon residue levels and preharvest intervals in green house Cucumbers in Jiroft, Journal of Genetic engineering and biosafety, Volume II, Number 1, 29 - Page 36 (In Persian)

[5] Arzi A, Hemmati AA, Nazari Khorasgani Z(2011), Determination and Comparison of the Organochlorine Pesticide Residue Levels Among Benni Fish of Shadegan, Mahshahr and Susangerd Cities, Khozestan Province in IRAN, Jundishapur Journal of Natural Pharmaceutical Products; 6(1): 24-31 